\title{
Reduction in the colonization of central venous cannulae by mupirocin
}

\author{
R. L. R. Hill and M. W. Casewell \\ Department of Medical Microbiology, King's College School of Medicine and \\ Dentistry, Bessemer Road, London SE5 8RX, UK
}

\begin{abstract}
Summary: In an in-vitro simulation of an intravascular cannula enclosed in a fibrin sheath, $0.03 \mathrm{mg} \mathrm{l}^{-1}$ of mupirocin prevented significant colonization [ $>15$ colony forming units (cfu)] by two clinical isolates of Staphylococcus epidermidis and one each of S. saprophyticus, S. hominis and S. haemolyticus. This suggests that in vivo, where protein binding of mupirocin is $95-97 \%$, $1 \mathrm{mg}^{-1}$ of mupirocin at the cannula surface would be required to prevent colonization.

These results support the findings of our previously published prospective controlled trial, in which mupirocin applied to the insertion sites of 172 internal jugular cannulae reduced the rate of colonization of cannula tips to $5 \%$, compared with $25 \%$ for the 186 controls $(P<0.001)$. Of the 46 colonized cannula tips from 110 control patients, the same species was isolated from the skin of the insertion site in $67 \%$ and from the lumen flush in only $15 \%$. Analysed by patient, mupirocin reduced the proportion of patients with colonized tips from $17 \%$ to $3 \%$ after $24 \mathrm{~h}$ of infection, and from 35 to $10 \%$ after $48 \mathrm{~h}(P=0.002)$. The use of agar containing charcoal, as a mupirocin neutralizer, and the incubation of tip-culture plates flooded with the Oxford staphylococcus, gave no evidence of carry over of mupirocin onto cannulae removed from mupirocin-treated patients.
\end{abstract}

Keywords: Intravenous cannulae; colonization; mupirocin; iodine; staphylococci.

\section{Introduction}

The proportion of central venous cannulae that give rise to septicaemia has been reported as $3 \cdot 8-21 \% .^{1-5}$ Although there is controversy as to whether the skin or the cannula hub is the source of organisms, ${ }^{6}$ several studies have confirmed a correlation between organisms cultured from the skin of the insertion site and those subsequently isolated from the cannula tip. ${ }^{7-12}$ Suppression of skin flora at the insertion site is therefore essential, and Maki ${ }^{13}$ has recommended disinfection of the skin with tincture of iodine. In a placebo-controlled trial we recently showed that local application of mupirocin to the site of insertion of internal jugular cannulae markedly reduces colonization of the cannula tip $;{ }^{14}$ these results are reviewed here with some new supporting in-vitro data. 


\section{Materials and methods}

In-vitro simulation

In vivo, the intravascular segment of the percutaneously inserted cannula becomes surrounded by a fibrin sheath which connects to the subcutaneous tract. ${ }^{15}$ In addition, it is thought that organisms from the skin at the insertion site enter the subcutaneous tract and reach the cannula tip by capillary action. ${ }^{16}$ The in-vitro arrangement shown in Figure 1 simulates the effect of mupirocin on the colonization of the cannula tip in the closed environment of a fibrin sheath. The procedure used was as follows:

(1) Doubling dilutions of mupirocin from $1 \cdot 0-0 \cdot 004 \mathrm{mg} \mathrm{l}^{-1}$ were made in $10 \mathrm{ml}$ aliquots of Iso-sensitest broth (Unipath CM473) contained in $30 \mathrm{ml}$ glass universal containers.

(2) $25 \mathrm{~mm}$ segments of 16 gauge 'Abbocath T' (Abbott Laboratories) cannulae were immersed in broth with (test), or without (control), mupirucin.

(3) For each experiment, test and control broths were inoculated with dilutions of overnight broth cultures of one of five test strains of coagulase-negative staphylococci. We used two clinical isolates of $S$. epidermidis (MICs 0.06 and $0.025 \mathrm{mg} \mathrm{l}^{-1}$ ), and one each of $S$. saprophyticus (MIC $0.03 \mathrm{mg} \mathrm{l}^{-1}$ ), S. hominis (MIC $0.12 \mathrm{mg} \mathrm{l}^{-1}$ ) and $S$. haemolyticus (MIC $0.03 \mathrm{mg} \mathrm{l}^{-1}$ ). The final inoculum was approximately $10^{2} \mathrm{cfu} \mathrm{ml}^{-1}$.

(4) After incubation at $37^{\circ} \mathrm{C}$ for $18 \mathrm{~h}$, cannula segments were removed from their broths and drained for $3 \mathrm{~min}$ on sterile filter paper.

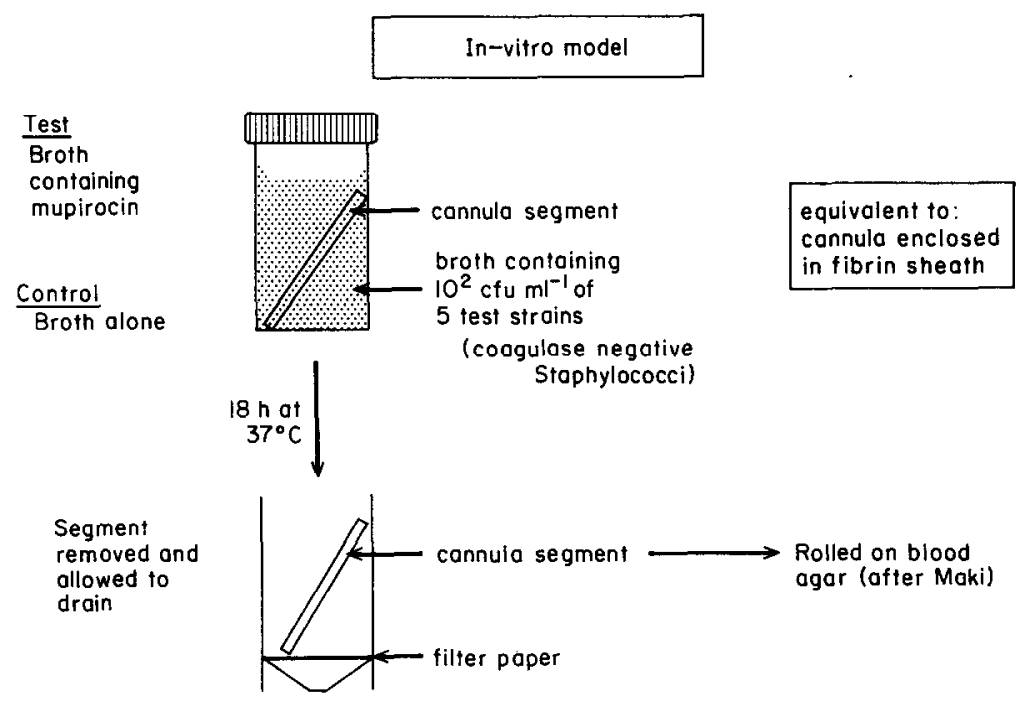

Figure 1. The in-vitro simulation. 
(5) Segments were then rolled back and forth five times on blood agar according to the method of Maki et al. ${ }^{17}$

\section{Controlled trial of mupirocin for the reduction of colonization of internal jugular cannulae}

In a prospective study reported previously in this fournal, ${ }^{14} 218$ cardiothoracic patients were randomized to receive skin preparation of the insertion site of 'Abbocath $T$ ' cannulae (inserted into the internal jugular vein) with tincture of iodine (108 controls) or tincture of iodine followed by application of sterile $2 \%$ calcium mupirocin ointment (110 test patients). Routine peri-operative chemoprophylaxis consisted of $80 \mathrm{mg}$ of gentamicin plus $500 \mathrm{mg}$ of flucloxacillin or $500 \mathrm{mg}$ of erythromycin for $48 \mathrm{~h}$. Cannulae were removed postoperatively, usually within $48 \mathrm{~h}$ of the operation, by a research control of infection nurse. At redressing and cannula removal, insertion sites were assessed for signs of local infection.

Before cannula removal, all traces of antibiotic ointment and iodine were removed from the insertion site. The skin was sampled for culture and then cleaned with an alcohol-impregnated swab. After removal of the cannula, $5 \mathrm{ml}$ of broth was flushed through the lumen and sent with the cannula to the laboratory. The detailed microbiological methods have been described elsewhere $^{18}$ and included semiquantitative culture of the tip and intracutaneous segments on blood agar according to the method of Maki et $a l .{ }^{17}$ followed by enrichment cultures. The lumen flush was also cultured directly and by enrichment. The possibility of carry-over of mupirocin on to the removed cannulae was assessed by three methods during weeks $3-6$ and 3-46 of the 37-week trial: firstly, by culture of 120 colonized cannula tips on blood agar with, and without, a neutralizer, namely $2 \%$ charcoal (Oxoid L9); 66 of these tips were from patients in the mupirocin group. Secondly, 120 skin swabs were also cultured on charcoal blood agar, 66 of which were from mupirocin-treated skin. Lastly, $0.5 \mathrm{ml}$ of an overnight broth culture of mupirocin-sensitive Oxford staphylococcus, diluted to give a semi-confluent growth (see Hill et al. ${ }^{14,18}$ ) was pipetted onto 120 incubated tip culture plates which were then re-incubated for $18 \mathrm{~h}$ and re-examined for zones of inhibition which, if present, might suggest the presence of mupirocin carried over at the time of inoculation with the cannula tip.

\section{Results}

\section{In-vitro simulation}

Cannula segments that had been immersed in control broths, without added mupirocin, yielded confluent growth from the rolled cannula segment. Figure 2 shows the influence of various concentrations of mupirocin on the recovery of each of the five test strains of coagulase-negative staphylococci from the cannula segments. At concentrations of $0.06 \mathrm{mg} \mathrm{l}^{-1}$, none of the 


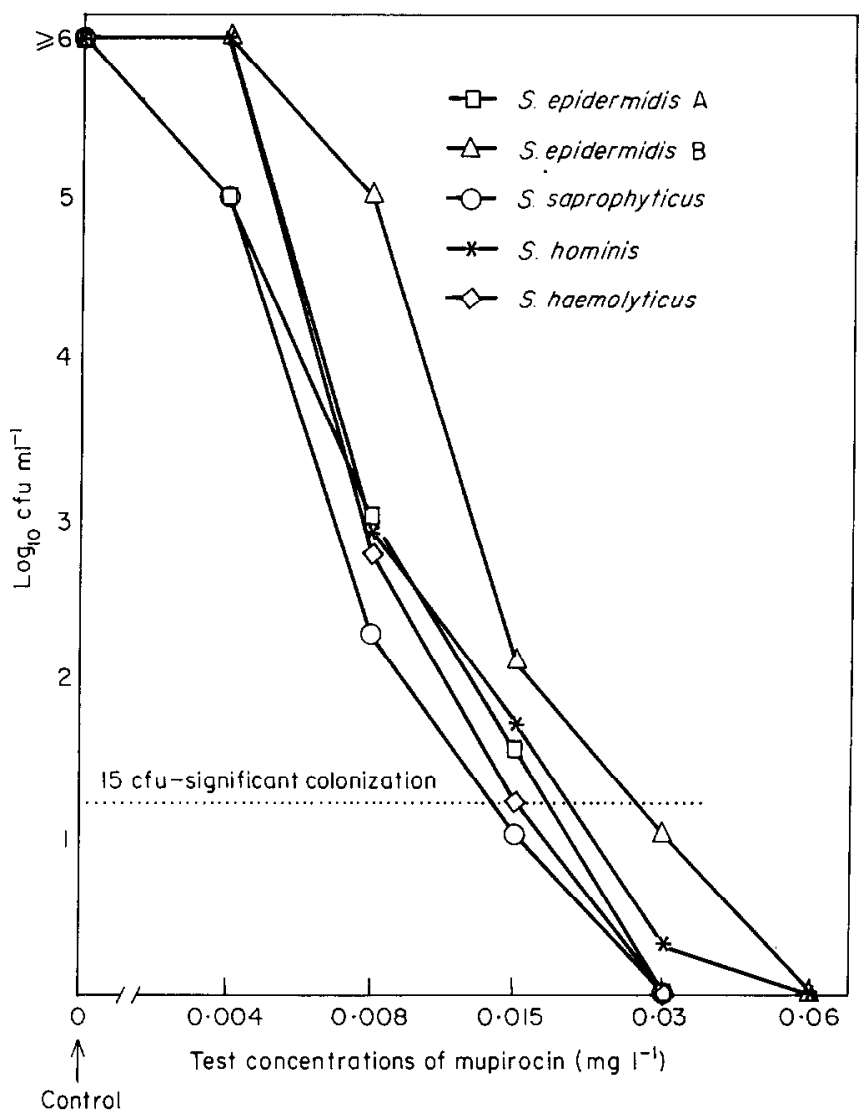

Figure 2. Colony counts from roll plates of cannulae exposed for $18 \mathrm{~h}$ to increasing concentrations of mupirocin.

five strains were recovered after $18 \mathrm{~h}$ incubation with the cannulae. As the concentration of mupirocin decreased so the number of recoverable cfus for each strain increased. A concentration of $0.03 \mathrm{mg} \mathrm{l}^{-1}$ of mupirocin was also adequate to prevent significant colonization of the cannula segments (i.e. $<15$ cfus). However, at $0.015 \mathrm{mg} \mathrm{l}^{-1}, 10 \mathrm{cfus}$ of $S$. hominis and $220 \mathrm{cfus}$ of strain B of $S$. epidermidis were recovered. In general, these differences seemed to correlate with the MIC of each organism: strain B of $S$. epidermidis had the highest MIC $\left(0.025 \mathrm{mg}^{-1}\right)$ and the highest number of cfus recovered at each concentration of mupirocin, whereas $S$. saprophyticus, which had an MIC of $0.03 \mathrm{mg} \mathrm{l}^{-1}$, yielded the lowest number of recoverable cfus. I Iowever, there were some strain differences which did not follow the MIC. For example, strain A of $S$. epidermidis, which had an MIC of $0.06 \mathrm{mg} \mathrm{l}^{-1}$, yielded fewer cfus when exposed to $0.004 \mathrm{mg} \mathrm{l}^{-1}$ of mupirocin than did the $S$. haemolyticus which had a lower MIC of $0.03 \mathrm{mg} \mathrm{l}^{-1}$. 


\section{Controlled trial}

'I'he results of this trial have been reported elsewhere ${ }^{14,18}$ and the main findings will be summarized here along with some previously unpublished data. The influence of mupirocin on the main source of organisms for the colonization of cannula tips will be further considered.

There were 108 patients in the control group and 110 in the mupirocin group (test), from whom 186 and 172 cannulae, respectively, were obtained. The features of patients and cannulae in test and control groups were evenly matched.$^{14}$ Mupirocin reduced the proportion of patients with significantly colonized cannula tips (i.e. recovery of $>15$ cfus) regardless of in-situ time (Table I). Within $24 \mathrm{~h}$ of insertion, $17 \%$ of control patients had colonized tips, compared with $3 \%$ of the test patients who had mupirocin applied to the insertion site. Table I also shows that the proportion of patients with colonized cannulae increased with in-situ time. By $48 \mathrm{~h}, 35 \%$ of control patients had colonized tips, and this increased to $66 \%$ for patients with cannulae in situ for 48-120 h. This increase with time was less marked for mupirocin-treated patients, of whom only $10 \%$ had colonized lines in situ for up to $48 \mathrm{~h}$. For the 17 test patients whose cannulae were in situ for $48-120 \mathrm{~h}$, none yielded $>15 \mathrm{cfu}$ from their cannula tips.

Analysis by cannulae (Table II) also showed that mupirocin reduced cannula colonization, regardless of in-situ time. In the control group, the intracutaneous segments were more often colonized than the tips: $32(45 \%)$ vs $24(34 \%)$, respectively for cannulae in situ for $>24-48 \mathrm{~h}$. However, in the mupirocin group, the colonization rates of tips and intracutaneous segments were similar: $10 \%$ vs $12 \%$ for tips and intracutaneous segments, respectively, for in-situ times of $>24-48 \mathrm{~h}$. Only $6(1 \cdot 7 \%)$ of lumen flush cultures were positive, three in the test and three in the control groups.

The results for the 358 cannulae obtained from 218 patients are shown in Table III. Overall, mupirocin reduced the proportion of colonized tips from $25 \%$ to $5 \%(P<0.001)$. Even by enrichment culture of any segment there were fewer cannulae yielding growth in the mupirocin group $(23 \%)$ compared with controls $(64 \%)(P<0.001)$. There was no significant difference in the incidence of erythema or pus at the 183 puncture sites in the control group or in the 164 sites in the mupirocin group that were assessed for signs of local infection.

Table I. Patients with one or more significantly colonized cannula tips

\begin{tabular}{lrcrccc}
\hline & \multicolumn{2}{c}{ Control patients } & & \multicolumn{2}{c}{ Mupirocin patients } & \\
\cline { 2 - 3 } $\begin{array}{l}\text { In-situ time } \\
\text { (h) }\end{array}$ & No. & $\begin{array}{c}\text { No. (\%) with } \\
\text { positive tip }\end{array}$ & & No. & $\begin{array}{c}\text { No (\%) with } \\
\text { positive tip }\end{array}$ & $\begin{array}{c}\text { Significance } \\
(P)\end{array}$ \\
\hline$<24$ & 98 & $16(17)$ & & 95 & $3(3)$ & 0.002 \\
$24<48$ & 68 & $24(35)$ & & 50 & $5(10)$ & 0.002 \\
$48-120$ & 9 & $6(66)$ & & 17 & 0 & $<0.001$ \\
\hline
\end{tabular}


Table II. Significant colonization of cannula segments according to in-situ time

\begin{tabular}{|c|c|c|c|c|c|c|}
\hline \multirow[b]{2}{*}{$\begin{array}{l}\text { Cannula } \\
\text { segment }\end{array}$} & \multirow[b]{2}{*}{$\begin{array}{l}\text { In-situ } \\
\text { time (h) }\end{array}$} & \multicolumn{2}{|c|}{ Control group } & \multicolumn{2}{|c|}{ Mupirocin group } & \multirow[b]{2}{*}{$P$ value } \\
\hline & & $\begin{array}{l}\text { No. of } \\
\text { cannulae }\end{array}$ & $\begin{array}{c}\% \\
\text { positive }\end{array}$ & $\begin{array}{l}\text { No. of } \\
\text { cannulae }\end{array}$ & $\begin{array}{c}\% \\
\text { positive }\end{array}$ & \\
\hline Tip & $\begin{array}{c}<24 \\
24-<48 \\
48-120\end{array}$ & $\begin{array}{r}105 \\
71 \\
10\end{array}$ & $\begin{array}{l}15 \\
34 \\
60\end{array}$ & $\begin{array}{r}103 \\
50 \\
19\end{array}$ & $\begin{array}{r}3 \\
10 \\
0\end{array}$ & $\begin{array}{l}<0.001 \\
<0.025 \\
<0.001\end{array}$ \\
\hline Intracutaneous & $\begin{array}{c}<24 \\
24<48 \\
48-120\end{array}$ & $\begin{array}{r}105 \\
71 \\
10\end{array}$ & $\begin{array}{l}23 \\
45 \\
70\end{array}$ & $\begin{array}{r}103 \\
50 \\
19\end{array}$ & $\begin{array}{r}5 \\
12 \\
10\end{array}$ & $\begin{array}{l}<0.001 \\
<0.01 \\
<0.025\end{array}$ \\
\hline Lumen flush & $\begin{array}{c}<24 \\
24<48 \\
48-120\end{array}$ & $\begin{array}{r}105 \\
71 \\
10\end{array}$ & $\begin{array}{l}1 \\
1 \\
1\end{array}$ & $\begin{array}{r}103 \\
50 \\
19\end{array}$ & $\begin{array}{l}1 \\
2 \\
0\end{array}$ & $\begin{array}{l}\text { NS* } \\
\text { NS* } \\
\text { NS* }\end{array}$ \\
\hline
\end{tabular}

$*$ NS $=$ Not significant.

Table III. Outcome for 186 control cannulae and 172 that were mupirocin-treated

\begin{tabular}{lccc}
\hline & \multicolumn{2}{c}{ No. of cannulae (\%) } & Significance \\
\cline { 2 - 3 } & Controls & Mupirocin & $(P)$ \\
\hline 15 cfu from tip & $46(25)$ & $8(5)$ & $<0.001$ \\
Any segment + ve by enrichment & $119(64)$ & $39(23)$ & $<0.001$ \\
Associated with local signs & $27(15)$ & $32(20)$ & NS* \\
\hline
\end{tabular}

*NS = Not significant.

Coagulase-negative staphylococci were the most frequent isolates, accounting for $62 \%$ of isolates from the control group and $19 \%$ of those from the test group. Micrococci and corynebacteria each accounted for $8 \%$ of isolates from control cannulae and 5\% from the test group. Staphylococcus aureus accounted for only $2 \%$ of isolates in the mupirocin group and $2 \%$ in the control group, whilst other organisms including the Enterobacteriaceae comprised $0 \cdot 5-3 \cdot 0 \%$. For $31(67 \%)$ of colonized cannula tips from control patients, the same species was also isolated from the skin of the insertion site. Only seven colonized cannulae $(15 \%)$ yielded organisms that were also found in the lumen flush. For the test group the skin was identified as the source of organisms for only two cannulae. Both of these isolates were mupirocin resistant $S$. epidermidis that were isolated from the skin before treatment with mupirocin. For mupirocin-treated patients there was only one cannula for which the tip isolate could be found in the lumen flush. 
Table IV. Influence of media on the rate of detection of significant colonization of cannula tips

\begin{tabular}{lcc}
\hline & $\begin{array}{c}\text { Control } \\
(N=54)\end{array}$ & $\begin{array}{c}\text { Mupirocin } \\
(N=66)\end{array}$ \\
\hline $\begin{array}{l}\text { Number of significantly colonized tips with } \\
\text { greater growth on media containing: } \\
\text { Blood }\end{array}$ & 13 & 5 \\
$\quad$ Blood + charcoal & 2 & 0 \\
\hline
\end{tabular}

Table IV shows that, of 120 cannulae, none yielded significant counts ( $>15 \mathrm{cfu}$ ) on charcoal blood agar alone. One significantly colonized tip was detected only on blood agar. None of the 120 skin swabs were positive on the charcoal whilst negative on blood agar but two were positive only on blood agar. When flooded with the Oxford staphylococcus, none of the cannula tip plates gave inhibition zones to suggest carry over of mupirocin.

\section{Discussion}

Our results show clearly that mupirocin can prevent colonization of central venous cannulae. In-vitro models have previously been used to investigate the influence of antimicrobial substances on the colonization of intravascular cannulae, ${ }^{19-23}$ but our in-vitro experiments mimic more closely the static environment of an intravascular cannula enclosed by a fibrin sleeve that is seeded from skin-derived organisms. ${ }^{15,24,25}$ In vivo, skin organisms may gain access to the cannula tip by capillary action. ${ }^{16}$

In our model, sub-inhibitory concentrations of mupirocin prevented significant colonization of central-venous cannula segments by five distinct strains of coagulase-negative staphylococci. This reduction of cannula colonization by sub-inhibitory concentrations has also been described for ciprofloxacin and fusidic acid. ${ }^{23}$ Sub-inhibitory concentrations of certain antibiotics are known to prevent bacterial adhesion, ${ }^{26}$ a prerequisite for colonization. Nevertheless, despite the possibility of beneficial sub-inhibitory effects, mupirocin did not prevent colonization of internal jugular cannulae by high-level mupirocin-resistant staphylococci derived from the insertion site in vivo. The effect of sub-inhibitory concentrations on more resistant organisms, and the effect of longer exposure times, warrants further investigation.

Microorganisms adhere to implanted surfaces via plasma-derived proteins which, for example, would be deposited on the surface of intravenous cannulae in vivo..$^{27-30}$ Because mupirocin is $95-97 \%$ protein-bound (Hill \& Casewell, unpublished observations) $c .1 .0 \mathrm{mg} \mathrm{l}^{-1}$ will be required to yield $0.03 \mathrm{mg} \mathrm{l}^{-1}$ of free mupirocin - the concentration 
shown in this study that is required to prevent significant colonization with sensitive staphylococci. Determination of the half-life of mupirocin ointment at the cannula insertion site would give an indication of the maximum interval before re-application of the ointment that would ensure continuous delivery of adequate concentations of mupirocin, i.e. $>1.0 \mathrm{mg} \mathrm{l}^{-1}$.

In our controlled trial, we applied ointment containing $2 \%$ calcium mupirocin $\left(20000 \mathrm{mg} \mathrm{l}^{-1}\right)$ directly to the puncture site in anticipation that sufficient mupirocin would diffuse down the subcutaneous tract to prevent colonization of the cannula tip. It was also envisaged that the addition of mupirocin would suppress any regrowth of skin flora. As skin disinfection has been shown to influence contamination of the cannula lumen," percutaneous insertion of the cannula through mupirocin might also decrease luminal contamination.

The results of the trial showed clearly that the application of mupirocin to the skin of the cannulation site after skin disinfection with tincture of iodine reduced significant colonization of cannulae inserted into the internal jugular vein from $25 \%$ to $5 \%(P<0 \cdot 001) .{ }^{14,18}$ For the test and control groups, both patients and cannulae were well matched. Previous studies on topical antibiotic ointments have usually investigated more heterogeneous groups of patients and indicated that local application of antibiotic ointment confers little, if any, benefit ${ }^{31-33}$ and may only be 'suitable' for peripheral lines. ${ }^{34}$ Although the majority of the patients studied were cannulated for $<48 \mathrm{~h}$ and were at low risk of acquiring a cannula-related bacteraemia, it is generally agreed that colonization is a prerequisite for bacteraemia and clinical cannula-related sepsis. ${ }^{35,36}$ The longer a colonized line is left in situ the greater the correlation of positive semi-quantitative cannula cultures with bacteraemia. ${ }^{37,38}$ In our study, mupirocin significantly reduced the proportion of patients with one or more colonized cannula tips regardless of in-situ time.

We took care to avoid carry over of ointment or iodine, at cannula removal. The use of agar containing charcoal, which served as a neutralizer ${ }^{39}$ did not improve the positivity rate of tip or skin cultures, and its use was thus discontinued. Indeed, charcoal agar often reduced bacterial growth, possibly by indiscriminant absorption of nutrients. Inoculation of a mupirocin-sensitive staphylococcus on to tip culture plates after incubation also failed to reveal evidence of antibiotic carry-over.

The application of mupirocin to the insertion site did not result in the isolation of mupirocin-resistant organisms such as Pseudomonas or Candida spp. The isolates from cannula tips corresponded most often to those cultured from the skin at the insertion site, rather than to the infrequent isolates from the cannula lumen. Mupirocin greatly reduced the skin flora with a corresponding decrease in the number of colonized tips. This supports the view that the skin of the insertion site, rather than the lumen, is the main source of organisms for colonization of the tip. ${ }^{7-12}$ However, we 
recognize that the junction between the cannula hub and the giving-set may assume importance with frequent make-and-break connections, for example during parenteral nutrition ${ }^{40-42}$ and haemodialysis. ${ }^{43}$

We conclude that application of mupirocin to the insertion site reduces the colonization of internal jugular cannulae by sensitive staphylococci. In addition, we suggest mupirocin has marked potential for the reduction of cannula-related sepsis caused by staphylococci in high-risk patients.

\section{References}

1. Michel L, McMichan JC, Bachy J. Microbial colonization of indwelling central venous catheters: statistical evaluation of potential contaminating factors. Surgery 1979; 137: 745-748.

2. Malmvall BE, Alestig K, Dottori O, Seeberg S. Septicaemia in patients with central vein catheters. Acta Chir Scand 1980; 146: 155-159.

3. Bozzetti F, Terno G, Camerini E, Baticci F, Scarpa D, Pupa A. Pathogenesis and predictability of central venous catheter sepsis. Surgery 1982; 91: 383-389.

4. Prager RL, Silva J. Colonisation of central venous catheters. South Med 7 1984; 77: 458-461.

5. Lindblad $B$, Wolff $T$. Infectious complications of percutaneously inserted central venous catheters. Acta Anaesthiol Scand 1985; 198: 48-52.

6. Sitges-Sera A, Linares J, Garu J. Catheter sepsis: the clue is the hub. Surgery 1985; 198: $350-355$.

7. Bjornson HS, Colley R, Bower RG, Duty VP, Schwartz-Fulton JT, Fischer JE. Association between microorganism growth at the catheter site and colonisation of the catheter in patients receiving total parenteral nutrition. Surgery 1982; 92: 720-725.

8. Snydman DR, Gorbea HF, Pober BR, Majka JA, Murray SA, Perry LK. Predictive value of surveillance skin cultures in total-parenteral nutrition-related infection. Lancet 1982; 2: 1385-1388.

9. Jakobsen C-JB, Grabe N, Damm MD. A trial of povidone-iodine for prevention of contamination of intravenous cannulac. Acta Anaesthesiol Scand 1986; 30: 447-449.

10. Cercenado E, Ena J, Soler J, Romero I, Rodriguez Creixems M, Bouza E. Origin of infection of intravascular cannulas (IVC). Abstract 272. Proceedings of the 28th Interscience Conference on Antimicrobial Agents and Chemotherapy. Los Angeles, California: American Society for Microbiology 1988.

11. Conly J, Grieves K, Peters B. Pathogenesis of catheter-related infection (CRI) in central venous catheters (CVC) using gauze (G) vs transparent (TP). Abstract 270. Proceedings of the 28th Interscience Conference on Antimicrobial Agents and Chemotherapy. Los Angeles, California; American Society for Microbiology 1988.

12. Maki DG. Sources of infection with central venous catheters in an ICU: a prospective study. Abstract 269. Proceedings of the 28th Interscience Conference on Antimicrobial Agents and Chemotherapy. Los Angeles, California: American Society of Microbiology 1988.

13. Maki DG. Infections associated with intravascular lines. In: Remington JS, Swartz MN, Eds. Current Topics in Infectious Diseases No 3. London: McGraw-Hill 1982; 309-363.

14. Hill RLR, Fisher AP, Ware RJ, Wilson S, Casewell MW. Mupirocin for the reduction of colonization of internal jugular cannulae - a randomised controlled trial. $\mathcal{F}$ Hosp Infect 1990; 15: 311-321.

15. Hoshal VL, Ause RG, I Ioskins PA, Arbor A. Fibrin sleave formation on indwelling subclavian central venous catheters. Arch Surg 1971; 102: 353-358.

16. Cooper GL, Schiller AL, Hopkins CC. Possible role of capillary action in pathogenesis of experimental catheter-associated dermal tunnel infections. F Clin Microbiol 1988; 26: $8-12$.

17. Maki DG, Weise CE, Saraffin HW. A semiquantitative culture method for identifying 
intravenous catheter-related infections. New England fournal of Medicine 1977; 296: 1395-1399.

18. Hill RLR, Fisher AP, Ware RJ, Wilson S, Casewell MW. Mupirocin: a new antibiotic that reduces colonisation of central venous cannulae by skin organisms. In Wadstrom $\mathrm{T}$, Eliasson I, Holder I, Ljungh A, Eds. Pathogenisis of Wound and Biomaterial-Associated Infections. London: Springer-Verlag 1990; 293-298.

19. Locci R, Peters G, Pulverer G. Microbial colonisation of prosthetic devices. I. Microtopographical characteristics of intravenous catheters as detected by scanning electron microscopy. Zentralbl Bakteriol Mikrobiol Hyg Abt I Orig B 1981; 175: 285-292.

20. Sugarman B, Young EJ. Infections Associated with Prosthetic Devices. Boca Raton, FL: CRC Press 1985.

21. Bayston R. A model of catheter colonisation in vitro and its relationship to clinical catheter infections. $\mathcal{F}$ Infect 1984; 9: 271-276.

22. Bayston $\mathbf{R}$, Zdroyewski V, Barsham S. Use of an in-vitro model for studying the eradication of catheter colonisation by Staphylococcus epidermidis. F Infect 1988; 16: 141-146.

23. Elliott 'TS, D'Abrera VC, Dutton S. The effect of antibiotics on bacterial colonisation of vascular cannulae in a novel in-vitro model. $\mathcal{F}$ Med Microbiol 1988; 26: 229-235.

24. Kido D, Paulin S, Alenghat J, Waternaux C, Riley W. Thrombogenicity of heparin and non-heparin coated catheters: clinical trial. Am $\mathcal{F}$ Radiol 1982; 139: 957-961.

25. Peters WR, Bush WH, McIntyre RD, Hill LD. The development of fibrin sheath on indwelling catheters. Surg, Gynecol Obstet 1973; 137: 43.

26. Shibl, AM. Effect of antibiotics on adherence of micro-organisms to epithelial cell surfaces. Rev Infect Dis 1985; 7: 51-65.

27. Peters G, Locci R, Pulverer G. Adherence and growth of coagulase-negative staphylococci on surfaces of intravenous eatheters. F Infect Dis 1982; 146: 479-482.

28. Vaudaux P, Suzuki R, Waldvogel F, Morgenthaler J. Nydegger U. Foreign body infection: role of fibronectin as a ligand for the adherence of Staphylococcus aureus. $\mathcal{F}$ Infect Dis 1984; 150: 546-553.

29. Herrmann M, Vaudaux PE, Pittet D et al. Fibronectin, fibrinogen, and laminin act as mediators of adherence of clinical staphylococcal isolates to foreign material. I Infect Dis 1988; 158: 693-701.

30. Vaudaux P. Host factors influencing staphylococcal foreign body infections. In Phillips, I. Focus on Coagulase-negative Staphylococci. International Congress and Symposium Series, Royal Society of Medicine Services Limited, London 1989; 17-25.

31. Levy RS, Goldstein J, Pressman RS. Value of a topical antibiotic vintment in reducing bacterial colonization of percutaneous venous catheters. $\mathcal{F}$ Albert Einstein Med Center 1970; 18: 67-70.

32. Norden CW. Application of antibiotic ointment to the site of venous catheterization-a controlled trial. $\mathcal{F}$ Infect Dis 1969; 120: 611-615.

33. Zinner SH, Denny-Brown BC, Braun P, Burke JP, Toala P, Kass EH. Risk of infection with indwelling catheters: effect of application of antibiotic ointment. $\mathcal{F}$ Infect Dis 1969; 120: 616-619.

34. Maki DG, Band JD. A comparative study of polyantibiotic and iodophor ointments in prevention of vascular catheter-related infection. Am Y Med 1981; 70: 739-744.

35. Gristina AG, Barth E, Webb LX, Myrvik QN. Microbial adhesion, molecular mechanisms and therapeutic strategies in biomaterial-and compromised tissue-centered infections. In Peterson PK, Fleer A, Eds. 3rd ECCM Symposium-Foreign Body-related Infections. The Hague: Excerpta Medica 1987; 26-35.

36. Tshefu K, Zimmerli W, Waldvogel FA. Short-term administration of rifampin in the prevention or eradication of infection due to forcign bodies. Rev Infect Dis 1983; 5 (Suppl. 3): $474-480$.

37. Sitges-Serra A, Linares J. Limitations of the semi-quantitative technique for catheter culture. $\mathcal{F}$ Clin Microbiol 1988; 26: 1074-1076.

38. Collignon PJ, Soni N, Pearson IY, Woods WP, Munro R, Sorrell TC. Is semiquantitative culture of central vein catheter tips useful in the diagnosis of catheter-associated bacteremia? F Clin Microbiol 1986; 24: 532-535.

39. Barr JG, Hogg GM. Value of charcoal media for recovering staphylococci incorporated in mupirocin ointment. $\mathcal{F}$ Clin Pathol 1987; 40: 372-376. 
40. Sitges-Serra A, Jaurrieta E, Linares J, Perez JL, Garau J. Bacteria in total parenteral nutrition catheters: where do they come from? Lancet 1983; 1: 531.

41. Sitges-Serra A, Puig P, Linares J et al. Hub colonization as the initial step in an outbreak of catheter-related sepsis due to coagulase-negative staphylococci during parenteral nutrition. F Parent Ent Nutr 1984; 8: 668-672.

42. Linares J, Sitges-Serra A, Garau J, Perez JL, Rogelio M. Pathogenesis of catheter sepsis: A prospective study with quantitative and semiquantitative cultures of catheter hub and segments. $\mathcal{F}$ Microbiol 1985; 21: 357-360.

43. Cheesbrough JS, Finch RG, Burden RP. A prospective study of the mechanisms of infection associated with haemodialysis catheters. $\mathcal{F}$ Infect Dis $1986 ; 154$ : 579-589. 